\title{
Vitreous fluorescein accumulation determined by in vivo fluorophotometry and by vitreous extraction in normal and diabetic rats
}

\author{
F. Kaufmann and C. Lacoste \\ F.Hoffmann-La Roche \& Co. Ltd. Pharma Research 3, Basel, Switzerland
}

\begin{abstract}
Summary. Vitreous fluorophotometry was performed on pigmented male rats (Piebald strain) 2 weeks after induction of diabetes by streptozotocin. In vivo fluorophotometry data were compared with measurements obtained by direct extraction of the vitreous $60 \mathrm{~min}$ after an intravenous injection of sodium fluorescein. In addition, the rate of fluorescein disappearance from blood plasma, plasma protein binding of fluorescein and the effect of insulin treatment of diabetic animals were investigated. Age-matched nondiabetic animals served as controls. In vivo fluorophotometric measurements showed a good correlation with fluorescein determinations after direct extraction of the vitreous. Vitreous fluorescein concentrations were similar in diabetic and normal rats and were strongly related to the dye plasma levels within each group of animals. In the diabetic rats, however, the elimination of plasma fluorescein was accelerated and the percentage of free fluorescein, as determined by ultrafiltration and equilibrium di-
\end{abstract}

alysis, was consistently higher $(130-150 \%$ of controls). The ratios of vitreous to total or free plasma fluorescein levels were elevated in diabetic rats. Experimental data indicate that plasma concentration of free fluorescein is crucial for vitreous dye accumulation. Insulin treatment of diabetic rats markedly improved their metabolic state and normalized the plasma fluorescein elimination and the vitreous to plasma fluorescein concentration ratios. It is concluded that vitreous fluorophotometry can be adequately applied to pigmented rats, provided that plasma fluorescein elimination rate and protein binding are considered in the interpretation of the results, since both influence the vitreous fluorescein accumulation and both may be altered by disease and drug treatment.

Key words: Rat, streptozotocin diabetes, vitreous fluorophotometry, vitreous fluorescein extraction, insulin, fluorescein pharmacokinetics, fluorescein protein binding.
Vitreous fluorophotometry, an in vivo method of assessing fluorescein levels in the vitreous body after a systemic application, was introduced some years ago in medical research. Ever since, several authors [1-3] have reported enhanced vitreous fluorescein concentrations in diabetic patients without angiographically detectable retinopathy. It was then suggested that elevated vitreous fluorescein levels may represent the earliest abnormality in developing diabetic retinopathy and indicate a breakdown of the blood retinal barrier. Tight metabolic control resulted in a normalization of the vitreous fluorophotometric readings [4]. Other groups have been unable to demonstrate any alteration between healthy and diabetic patients without observable retinopathy $[5,6]$. The technique was also applied to study the effect of experimentally induced diabetes by streptozotocin or pancreatectomy on the blood retinal barrier in rats. As in studies on man, these studies yielded conflicting results. Elevated vitreous fluorescein levels [7, 8] in diabetic rats which could be normalized by insulin treatment
$[9,10]$, as well as no differences between normal and diabetic rats, have been reported $[11,12]$. Technical difficulties $[13,14]$ in measuring vitreous fluorescein levels in rats and biological factors $[11,14]$ such as metabolic state and strain differences of the animals might have caused these inconsistent data. Parameters which influence the vitreous readings such as plasma fluorescein pharmacokinetics and fluorescein protein binding were also not sufficiently considered [15]. We therefore performed vitreous fluorophotometry in nondiabetic and streptozotocin-diabetic pigmented rats under strictly defined experimental conditions with regard to plasma fluorescein elimination and fluorescein protein binding as well as to metabolic data.

In order to evaluate the reliability of our in vivo fluorophotometric readings, the vitreous fluorescein concentrations were also measured by extraction of the vitreous directly after the in vivo determinations. Finally, the influence of insulin treatment on vitreous fluorescein accumulation in diabetic rats was investigated. 


\section{Materials and methods}

\section{Animals}

Male SPF Piebald (pigmented) rats were obtained from the Institut für Biologisch-Medizinische Forschung, Füllinsdorf, Switzerland. Approximately 1 week after their transfer to the local animal room $\left(23{ }^{\circ} \mathrm{C}, 50 \%-60 \%\right.$ relative humidity) the rats $(180-220 \mathrm{~g}$ body weight, aged 9-11 weeks) were fasted for $24 \mathrm{~h}$ before streptozotocin (F. Hoffmann-La Roche, Basel, Switzerland: $70 \mathrm{mg} / \mathrm{kg}$ ) was injected subcutaneously under light Nembutal (Abbott AG, Zug, Switzerland: $35 \mathrm{mg} / \mathrm{kg}$ intraperitoneally) anaesthesia. Age- and weight-matched untreated rats served as controls. In all experiments the animals had free access to food (Nafag 850: Nafag AG, Gossau, Sitzerland) and drinking water.

\section{Vitreous fluorophotometry}

The rats were anaesthetized with Nembutal $(50 \mathrm{mg} / \mathrm{kg}$ intraperitoneally). A solution of $10 \%$ sodium fluorescein $(0.04-0.10 \mathrm{ml} /$ animal $)$ was injected intravenously into the dorsal penile vein $1 \mathrm{~h}$ before performing vitreous fluorophotometry. For the readings the pupils were maximally dilated by Neosynephrine (Winthrop Lab., New York, USA) and Mydriaticum Dispersa (Dispersa AG, Winterthur, Switzerland) and a contact lens was placed on the eye. Midvitreous fluorescein levels were measured by a vitreous fluorophotometer consisting of a modified Haag-Streit slit lamp (Model 900) fitted with a $150 \mu \mathrm{m}$ diameter photometric probe (Gamma Scientific Inc. 700-10-37, San Diego, CA, USA) and excitation (Balzers AG FITC 5, Balzers, Liechtenstein) and barrier filters (Spectrotech SE 50, Lincoln, MA, USA). Slit width was $0.15 \mathrm{~mm}$, and the illumination detection angle was $16^{\circ}$. The photometric probe was focused at the midpoint of the vitreous. The resolution power of our setup was $1.4 \mathrm{~mm}$. Light signals passed through a photomultiplier tube (Gamma Scientific D46A, San Diego. CA, USA) and were displayed on a digital display radiometer (Gamma Scientific DR-IA) which was connected to a X-Y plotter. Calibration was performed using freshly prepared fluorescein solutions in phosphate buffered saline (PBS, pH 7.4), and was made before and at regular intervals during the measurements. The detection limit was $5 \times 10^{-9} \mathrm{~g} / \mathrm{ml}$.

Autofluorescence of the midvitreous in our pigmented rats was below the detection limit and did not influence the readings $1 \mathrm{~h}$ after fluorescein injection. Vitreous fluorescein concentrations are given in absolute values $(\mathrm{ng} / \mathrm{ml})$ or are related to the $1 \mathrm{~h}$ total or free plasma fluorescein levels or to the integral of plasma fluorescein 5 to $60 \mathrm{~min}$ after dye application. Integral was calculated by simple arithmetics as described by Kjaergaard [16] by subdividing the area under the fluorescein plasma concentration curve in trapezoids. For these calculations total plasma fluorescein levels at $5,15,30$ and 60 min after dye application were considered.

\section{Fluorescein extraction from the vitreous}

Immediately after the in vivo measurements the animals were decapitated, and their eyes were enucleated and frozen in liquid nitrogen. The frozen eyeballs were cut along the equator by a scalpel. Frozen vitreous could then be easily removed, weighed and homogenized with $1 \mathrm{ml}$ of $0.1 \mathrm{~mol} / 1 \mathrm{NaOH}$. Fluorescein concentration of this extract was determined by a fluorimeter (Aminco Bowman, American Instrument Company, Silver Spring, MD, USA). Vitreous fluorescein concentrations were expressed as $\mathrm{ng} / \mathrm{g}$ vitreous body.

\section{Total plasma fluorescein}

Blood was taken from the tip of the tail or after decapitation at various times after the fluorescein application, and collected in chilled heparinized or EDTA coated tubes. Plasma was prepared by centrifugation at $5600 \mathrm{~g}$ for $5 \mathrm{~min}$. Plasma fluorescein concentrations were measured after appropriate dilution with PBS by the fluorimeter.

\section{Free plasma fluorescein}

For the determination of free fluorescein in plasma, ultrafiltration and equilibrium dialysis were used. Only plasma from trunk blood after decapitation was assessed. Ultrafiltration was made by means of the micropartition system (Amicon MPS-1 YMT membranes, W. Meyer, Lucerne, Switzerland). Plasma $(400 \mu l)$ was centrifuged at $4{ }^{\circ} \mathrm{C}$ for $15 \mathrm{~min}$ at $1250 \mathrm{~g}$ after $1 \mathrm{~h}$ preincubation at $4{ }^{\circ} \mathrm{C}$. This procedure yielded about $150 \mu 1$ filtrate containing free fluorescein. Equilibrium dialysis was performed by means of an equilibrium dialyzer (F.Hoffmann-La Roche \& Co., Ltd., Basel, Switzerland). Dialysis membranes (Union Carbide $18 \mathrm{FO} \times 100 \mathrm{FF}, 6000-8000$ molecular weight cutoff; Werthemann \& Co., Basel, Switzerland) were prepared by soaking in $0.1 \mathrm{~mol} / 1$ phosphate buffer $(\mathrm{pH} 7.24)$ for $1 \mathrm{~h}$. The dialysis was performed at $37^{\circ}$ for $4 \mathrm{~h}$. After this time the equilibrium was reached. At the end of dialysis the fluorescein concentration on the buffer side and at the plasma side were assessed (end $\mathrm{pH}$ 7.4). Percentage of free fluorescein was calculated from the ratio of the concentration on the buffer side to the concentration on the plasma side. Blood and urinary glucose levels were determined by an enzymatic method using the Glucoquant kit (Boehringer No. 253826, Mannheim, FRG). Glycosylated haemoglobin was estimated by affinity chromatography (Pierce No. 4200, Rockford, NY, USA). Nonesterified fatty acids from plasma were analyzed by automated titration as described earlier [17].

\section{Statistical analysis}

Results are expressed as mean \pm SEM. Comparisons were made with the unpaired Student's t-test and correlations by linear regression analysis.

\section{Experimental protocols}

Rats of the same age and initial body weight were used in all experiments. Diabetic animals were investigated 2 weeks after streptozotocin injection in comparison with age-matched controls. The metabolic state of the rats was characterized by determination of blood glucose levels under free feeding conditions and body weight.

\section{Plasma fluorescein elimination and fluorescein protein binding}

Groups of normal and diabetic animals were decapitated 5, 15, 30 and $60 \mathrm{~min}$ after an intravenous application of $0.06 \mathrm{ml}$ of $10 \%$ sodium fluorescein per animal. Total plasma fluorescein concentration was assessed in EDTA-plasma. The percentage of free fluorescein was measured by ultrafiltration.

\section{Vitreous fluorescein accumulation, total plasma fluorescein levels and fluorescein protein binding in normal and diabetic rats in relation to various doses of sodium fluorescein}

One hour after an intravenous injection of $0.04,0.06,0.08$ and $0.10 \mathrm{ml}$ of $10 \%$ sodium fluorescein per animal, vitreous fluorophotometry was performed. Immediately after the in vivo readings, the animals were decapitated. Fluorescein concentration was determined in the vitreous after extraction and in heparinized plasma. Equilibrium dialysis and ultrafiltration were applied to determine the percentage of free fluorescein. As both methods produced identical binding data, only the values measured by equilibrium dialysis are presented. 


\section{Effect of insulin treatment on vitreous fluorescein accumulation, plasma fluorescein elimination and plasma protein binding of the dye in diabetic rats}

Twenty-four male Piebald rats were made diabetic by streptozotocin. Starting on the next day, half of the animals were insulin treated (Protamin Zinc Insulin, Ely Lilly, Indianapolis, IN, USA: 1 U/animal at $08.00 \mathrm{~h}$ and $2 \mathrm{U} /$ animal at $16.00 \mathrm{~h}$ subcutaneously). Ten age-matched normal (i.e. nondiabetic) rats served as further controls. Two weeks after diabetes induction the animals were subjected to vitreous fluorophotometry. Insulin-treated animals got their last dose the evening before. Each animal received $0.06 \mathrm{ml}$ of $10 \%$ sodium fluorescein intravenously. One hour later the fluorophotometric readings were performed. Immediately after the in vivo measurements, the animals were decapitated and the fluorescein concentration in the vitreous after extraction and in heparinized plasma was determined. The per-

Table 1a. Vitreous fluorescein accumulation, total plasma fluorescein levels and fluorescein protein binding in normal and diabetic rats in relation to various doses of fluorescein (60 $\mathrm{min}$ after dye injection)

\begin{tabular}{|c|c|c|c|c|c|}
\hline \multirow{2}{*}{\multicolumn{2}{|c|}{$\begin{array}{l}\mathrm{ml} \text { of } 10 \% \text { sodium } \\
\text { fluorescein injected } \\
\text { per animal }\end{array}$}} & \multicolumn{2}{|c|}{$\begin{array}{l}\text { Vitreous fluorescein } \\
\text { concentration }\end{array}$} & \multicolumn{2}{|c|}{$\begin{array}{l}\text { Plasma fluorescein } \\
\text { concentration }\end{array}$} \\
\hline & & $\begin{array}{l}\text { Fluoro- } \\
\text { photom- } \\
\text { etry } \\
(\mathrm{ng} / \mathrm{ml})\end{array}$ & $\begin{array}{l}\text { Extraction } \\
\text { method (ng/g } \\
\text { vitreous wet } \\
\text { weight) }\end{array}$ & $\begin{array}{l}\text { Total } \\
(\mu \mathrm{g} / \mathrm{ml})\end{array}$ & $\begin{array}{l}\% \text { Free } \\
\text { (equilibrium } \\
\text { dialysis) }\end{array}$ \\
\hline \multicolumn{6}{|l|}{0.04} \\
\hline Control rats & $(n=5)$ & $98 \pm 11$ & $85 \pm 7$ & $9.7 \pm 1.1$ & $12.9 \pm 0.3$ \\
\hline Diabetic rats & $(n=5)$ & $82 \pm 5$ & $72 \pm 6$ & $2.9 \pm 0.2$ & $17.6 \pm 0.5$ \\
\hline$p$ & & NS & NS & $<0.01$ & $<0.01$ \\
\hline \multicolumn{6}{|l|}{0.06} \\
\hline Control rats & $(n=5)$ & $132 \pm 9$ & $153 \pm 12$ & $16.1 \pm 2.1$ & $12.6 \pm 0.7$ \\
\hline Diabetic rats & $(n=5)$ & $129 \pm 16$ & $128 \pm 13$ & $4.0 \pm 0.6$ & $17.9 \pm 0.6$ \\
\hline$p$ & & NS & NS & $<0.01$ & $<0.01$ \\
\hline \multicolumn{6}{|l|}{0.08} \\
\hline Control rats & $(n=5)$ & $219 \pm 19$ & $161 \pm 21$ & $19.7 \pm 2.8$ & $14.4 \pm 0.8$ \\
\hline Diabetic rats & $(n=5)$ & $217 \pm 11$ & $153 \pm 9$ & $4.4 \pm 0.2$ & $18.2 \pm 1.2$ \\
\hline$p$ & & NS & NS & $<0.01$ & $<0.05$ \\
\hline \multicolumn{6}{|l|}{0.10} \\
\hline Control rats & $(n=5)$ & $329 \pm 30$ & $255 \pm 22$ & $48.4 \pm 5.0$ & $13.1 \pm 0.7$ \\
\hline Diabetic rats & $(n=5)$ & $314 \pm 30$ & $247 \pm 24$ & $10.4 \pm 1.8$ & $20.7 \pm 0.3$ \\
\hline$p$ & & NS & NS & $<0.01$ & $<0.01$ \\
\hline
\end{tabular}

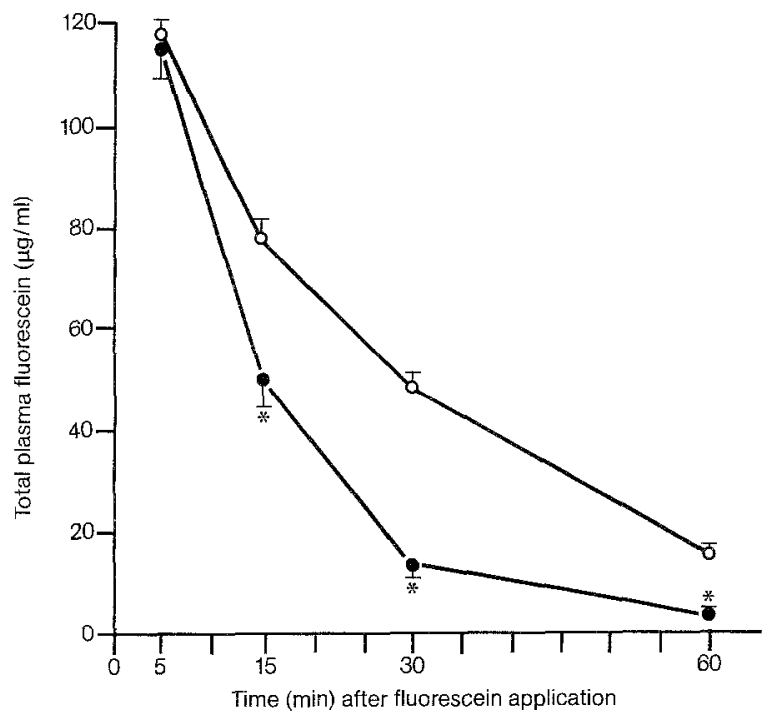

Fig. 1. Time course of total plasma fluorescein levels in normal (O) and diabetic ( $)$ rats after an intravenous application of $10 \%$ sodium fluorescein $(0.06 \mathrm{ml}$ per rat). Vertical lines indicate SEM for groups of 5 rats. ${ }^{*} p<0.01$ versus control rats

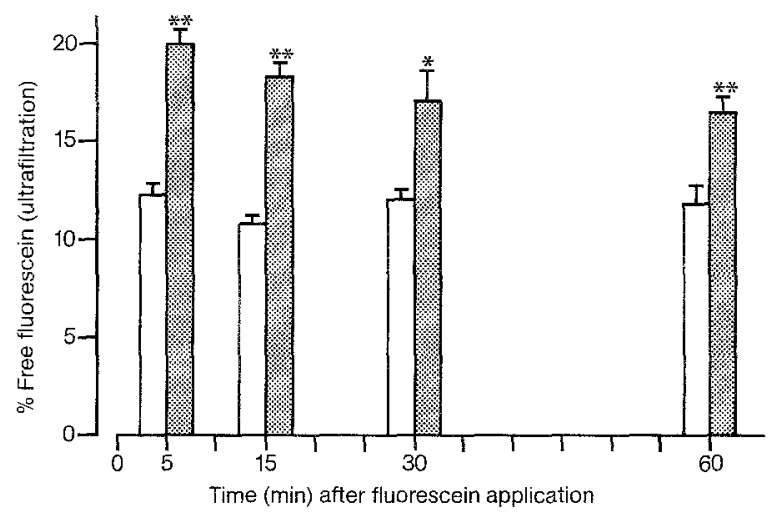

Fig. 2. Plasma protein binding of fluorescein in normal $(\square)$ and diabetic (\$) rats at different times after an intravenous application of $10 \%$ sodium fluorescein $(0.06 \mathrm{ml}$ per rat). Vertical lines indicate SEM for groups of 5 rats. ${ }^{*} p<0.05, * * p<0.01$ versus control rats

Table 1 b. Calculated ratios of vitreous fluorescein determined by in vivo fluorophotometry to plasma fluorescein in normal and diabetic rats

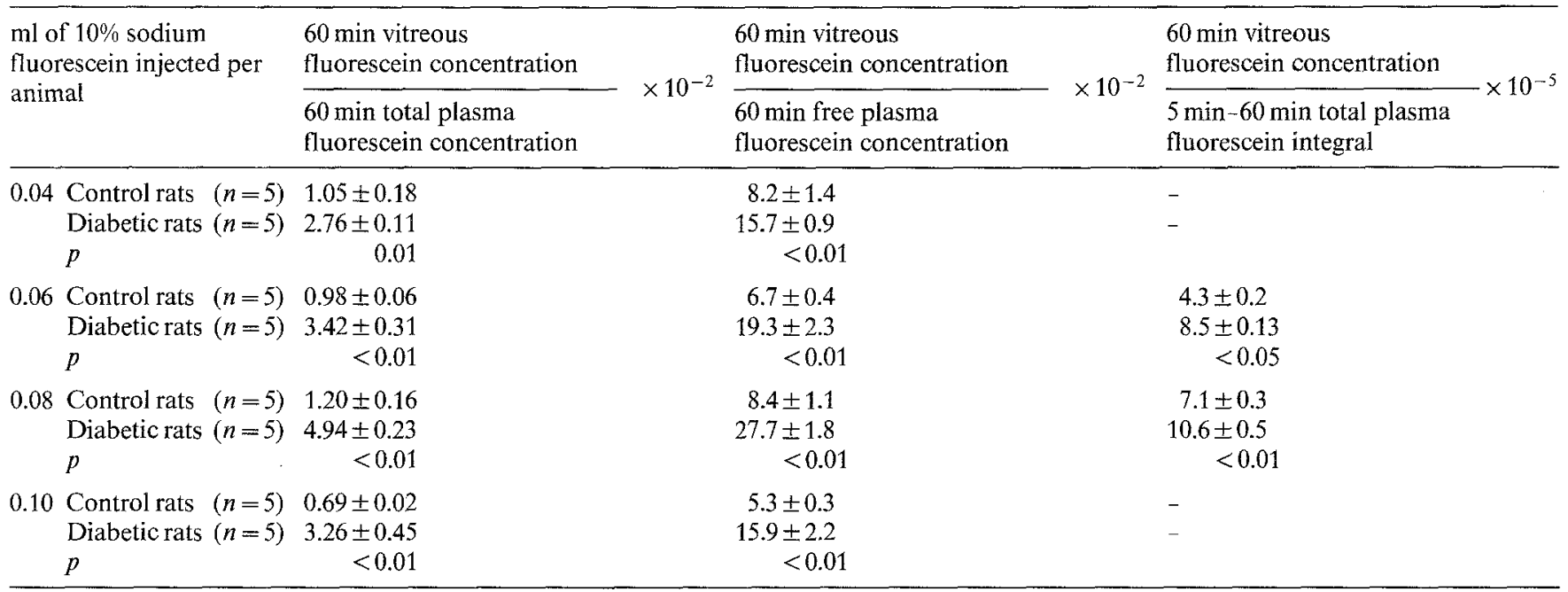

Results are expressed as mean $\pm \mathrm{SEM}$ 
centage of free fluorescein was measured by equilibrium dialysis and ultrafiltration. Again both methods yielded identical results. Therefore, only data obtained by equilibrium dialysis are presented. In addition, total plasma fluorescein (tail blood) was measured $15 \mathrm{~min}$ after dye application. The effect of diabetes treatment by insulin was estimated by measuring blood glucose and glycosuria one week after the streptozotocin application. At the end of the experiment blood glucose, glycosylated haemoglobin, body weight and nonesterified fatty acids were determined.

\section{Results}

\section{Plasma fluorescein elimination and fluorescein protein} binding in normal and diabetic rats

Plasma fluorescein concentration was seen to decrease rapidly during the $60 \mathrm{~min}$ experimental period (Fig. 1). Total plasma fluorescein concentration was significantly lower in diabetic rats at 15,30 and $60 \mathrm{~min}$ after dye injection. The percentage of free fluorescein was higher in diabetic rats at any time but remained virtually constant during the measuring period in both normal and diabetic animals respectively (Fig. 2). Diabetic rats showed a comparable hyperglycaemia (22.7 \pm $0.7 \mathrm{mmol} / 1$ versus $6.7 \pm 0.2 \mathrm{mmol} / 1$ in controls, $p<$ $0.01)$ and weighed $21 \%$ less than control rats $(196 \pm 6 \mathrm{~g}$ versus $249 \pm 5, p<0.01$ ).

\section{Vitreous fluorescein accumulation, total plasma fluorescein and fluorescein protein binding in normal and diabetic rats in relation to various doses of sodium fluorescein (Tables $1 \mathrm{a}, \mathrm{b}$ )}

After intravenous injection of increasing doses of sodium fluorescein, proportionate vitreous fluorescein levels were found $1 \mathrm{~h}$ after injection by in vivo and in vitro measurements (Table $1 \mathrm{a}$ ). There was a good correlation between the slit lamp readings and the in vitro (extraction) method $(r=0.92)$. As expected, the 1-h total plasma fluorescein concentrations were also increased in a dose-dependent manner. No difference was found in the absolute fluorescein concentration of the vitreous between normal and diabetic animals at any dose. However, plasma dye concentrations in diabetic animals were found to be substantially lower than control values at any fluorescein dose. The percentage of free fluorescein had always been higher in the plasma of diabetic rats. Within each group highly positive correlations were found between vitreous fluorescein and total plasma fluorescein (control rats $r=0.92$, diabetic rats $r=0.85$ ) as well as free plasma fluorescein levels (control rats $r=0.91$, diabetic rats $r=0.84$ ). When the vitreous readings were related to the $1 \mathrm{~h}$ free or total plasma fluorescein or to the integral of total plasma fluorescein (determined for the $0.06 \mathrm{ml}$ and $0.08 \mathrm{ml}$ dose), significant elevations in the vitreous to plasma fluorescein ratios were found in diabetic rats compared with control animals for any fluorescein dose injected (Table $1 \mathrm{~b}$ ). Provided that the fluorescein binding remained constant during the experimental period, the ratios of vitre- ous to free plasma fluorescein integral can be calculated. These ratios were also slightly, though not significantly, elevated in diabetic rats $(0.06 \mathrm{ml}$ fluorescein dose: $4.67 \pm 0.58 \times 10^{-4}$ versus $3.44 \pm 0.26 \times 10^{-4}$ in control rats; $0.08 \mathrm{ml}$ fluorescein dose: $5.90 \pm 0.22 \times 10^{-4}$ versus $5.27 \pm 0.38 \times 10^{-4}$ in control rats). Again, diabetic rats had markedly elevated blood glucose values $(21.7 \pm 0.7 \mathrm{mmol} / 1$ versus $6.8 \pm 0.2 \mathrm{mmol} / 1$ in controls, $p<0.01)$ and weighed $24 \%$ less than controls $(222 \pm 7 \mathrm{~g}$ versus $294 \pm 10 \mathrm{~g}, p<0.01$ ).

\section{Effect of insulin treatment on vitreous fluorescein accumulation, plasma fluorescein elimination and on plasma protein binding of the dye in diabetic rats (Tables 2a, b)}

Insulin treatment considerably improved the metabolic state of diabetic rats (Table 2a). Treated animals showed an increased weight gain, reduced blood glucose- and glycosylated haemoglobin levels and diminished glycosuria compared with non-insulin-treated diabetic rats. At termination of the experiment, $16 \mathrm{~h}$ after the last insulin dose, blood glucose was only moderately lower in treated than in nontreated diabetic rats, whereas no difference in plasma concentrations of nonesterified fatty acids between these two groups was found. Five diabetic animals died within the first week after streptozotocin. Fluorescein application had failed in one diabetic and one insulin-treated animal. Vitreous fluorescein concentration measured by vitreous fluorophotometry or by the extraction method (in vitro) was the same in normal and untreated diabetic rats (Table 2b). Insulin-treated rats displayed moderately higher concentrations than animals from the two other groups. Total plasma fluorescein concentrations were identical in normal and insulin-treated diabetic animals 15 and $60 \mathrm{~min}$ after dye application, but were markedly decreased in untreated diabetic rats. The percentage of free fluorescein was the same in untreated and insulintreated diabetic rats, and was higher than in controls. This means that the absolute plasma levels of free fluorescein were higher in the insulin-treated animals than in the control or untreated diabetic rats. Correction of vitreous fluorescein levels for the 1-h free plasma fluorescein levels yielded no statistically significant differences of vitreous to plasma ratios between normal and insulin-treated diabetic rats. Untreated diabetic rats again had massively elevated ratios.

\section{Discussion}

We performed vitreous fluorophotometry in normal and diabetic rats under strictly defined experimental conditions. Only pigmented rats were used to minimize light scattering artefacts excessively present in albinotic eyes. By dosing the fluorescein per animal (not per body weight), we measured identical plasma levels in normal and diabetic rats $5 \mathrm{~min}$ after the dye administration. At 
any time later, total plasma fluorescein concentrations were considerably lower in diabetic rats. That could be caused by the increased glomerular filtration rate in diabetic rats [18], an altered fluorescein metabolism or a generally increased vascular permeability. The percentage of free fluorescein was always higher $(130-150 \%)$ in plasma of diabetic rats. This may be due to the higher concentration of nonesterified fatty acids, since they affect (usually decrease) the plasma protein binding [19]. An altered fluorescein metabolism in diabetic animals could also play a role. Fluorescein is glucuronized in rats [20] and fluorescein glucuronides have been de-

Table 2a. Effect of insulin treatment on metabolic state of diabetic rats

\begin{tabular}{|c|c|c|c|}
\hline & $\begin{array}{l}\text { Control rats } \\
(n=10)\end{array}$ & $\begin{array}{l}\text { Diabetic rats } \\
(n=7)\end{array}$ & $\begin{array}{l}\text { Insulin-treat- } \\
\text { ed diabetic } \\
\text { rats }(n=12)\end{array}$ \\
\hline Body weight (g) & $310 \pm 6$ & $230 \pm 4^{a}$ & $285 \pm 3^{b c}$ \\
\hline \multicolumn{4}{|l|}{$\begin{array}{l}\text { Blood glucose } \\
(\mathrm{mmol} / \mathrm{l})\end{array}$} \\
\hline $\begin{array}{l}-4 \mathrm{~h} \text { after the } \\
\text { morning insulin } \\
\text { dose }\end{array}$ & $5.3 \pm 0.1$ & $23.4 \pm 0.8^{\mathrm{a}}$ & $7.7 \pm 1.5^{c}$ \\
\hline $\begin{array}{l}\text { - 16h after the last } \\
\text { insulin dose }\end{array}$ & $6.6 \pm 0.2$ & $23.7 \pm 1.9^{\mathrm{a}}$ & $18.2 \pm 0.6^{\text {bd }}$ \\
\hline $\begin{array}{c}\text { Glycosylated hae- } \\
\text { moglobin }(\%)\end{array}$ & $4.2 \pm 0.1$ & $10.2 \pm 0.2^{\mathrm{a}}$ & $6.0 \pm 0.1^{b c}$ \\
\hline $\begin{array}{l}\text { Glycosuria (mmol/ } \\
24 \mathrm{~h})\end{array}$ & - & $82.2 \pm 3.0$ & $22.8 \pm 3.5^{\mathrm{c}}$ \\
\hline $\begin{array}{l}\text { Non-esterified fatty } \\
\text { acids }(\mu \mathrm{mol} / 1)\end{array}$ & $473 \pm 26$ & $728 \pm 33^{a}$ & $724 \pm 35^{b}$ \\
\hline
\end{tabular}

Results expressed as mean \pm SEM. ${ }^{\mathrm{a}} p<0.001$ Diabetic versus control rats; ${ }^{b} p<0.001$ insulin-treated diabetic versus control rats; ${ }^{c} p<0.001$ insulin-treated diabetic versus diabetic rats; ${ }^{\mathrm{d}} p<0.01$ insulin-treated diabetic versus diabetic rats scribed to be less protein bound than fluorescein itself [21]. Whether glucuronidation is altered in diabetic compared with normal rats is not yet known. Nonenzymatic glycosylation of serum proteins seems not to affect fluorescein protein binding [22]. In vivo vitreous fluorophotometry readings and fluorescein determinations performed immediately thereafter by extraction of the isolated vitreous yielded well correlating results $(r=0.9)$. Although the diameter in rat vitreous is small (about $1.8 \mathrm{~mm}$ ) and the resolution power of our equipment is $1.4 \mathrm{~mm}$, our readings at lower fluorescein doses $(0.04 \mathrm{ml}, 0.06 \mathrm{ml})$ were neither affected by fluorescein still present in the retina or the choroid nor by lens autofluorescence, since the extraction procedure gave the same results. With higher fluorescein doses $(0.08 \mathrm{ml}$, $0.1 \mathrm{ml}$ ), the higher dye concentrations in the retina and choroid might have caused the moderately elevated in vivo readings compared with the in vitro measurements. However, by neither the in vivo nor the extraction method did we ever measure a significant difference of the vitreous fluorescein between normal and diabetic rats. We did show that the vitreous fluorescein levels were strongly dependent on the injected fluorescein dose, i.e. the plasma fluorescein levels. For interpretation, vitreous fluorescein must therefore be related to plasma fluorescein levels, with the plasma fluorescein integral the most relevant. The relation to the $1-\mathrm{h}$ dye concentration may serve as an approximation (e.g. if repeated blood sampling is not possible). All these ratios were enhanced in our diabetic rats. Nevertheless, our results do not enable us to conclude that there is a pathological leakage of the blood retinal barrier in our diabetic rats. First, we still do not know where the fluorescein we measure comes from. Choroid, retina and iris vessels are the possible candidates. Second, assuming that mainly the free fluorescein penetrates into the vitreous,

Table $\mathbf{2 b}$. Effect of insulin treatment on vitreous fluorescein accumulation, total plasma fluorescein and fluorescein protein binding in diabetic rats

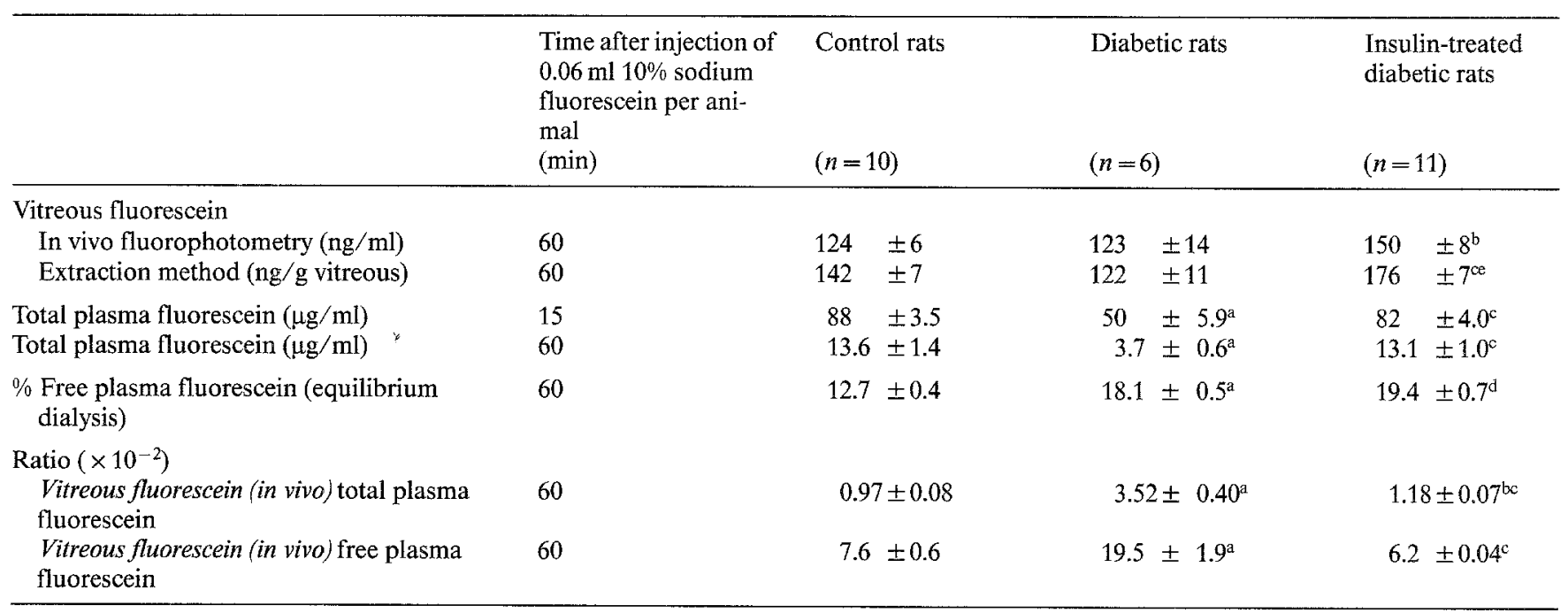

Results expressed as mean $\pm \mathrm{SEM} ;{ }^{\mathrm{a}} p<0.001$ diabetic versus control rats $;{ }^{\mathrm{b}} p<0.05$ insulin-treated diabetic versus control rats; ${ }^{\mathrm{c}} p<0.001$ insulintreated diabetic versus non-insulin-treated diabetic rats; ${ }^{\mathrm{d}} p<0.001$ insulin-treated diabetic versus control rats; ${ }^{\mathrm{e}} p<0.01$ insulin-treated diabetic versus control rats 
the relevant ratio of vitreous to free plasma fluorescein integral was slightly and not significantly enhanced in our diabetic rats $(135 \%$ of controls for the $0.06 \mathrm{ml}$ fluorescein dose and $112 \%$ for the $0.08 \mathrm{ml}$ dose in experiment 2). Third, glucuronidation of fluorescein (not measured in our experiments) might further complicate the situation [23]. It is not yet clear how much free or glucuronized fluorescein contributes to the dye accumulation in the vitreous. Using radioactive labeled tracers $\left({ }^{51} \mathrm{Cr}\right.$ edetic acid and ${ }^{3} \mathrm{H}-\mathrm{l}$ glucose), Maepa et al. [24] could not detect a pathologic permeability of the blood retinal barrier in diabetic rats. Other authors reported that pathological changes in pigment epithelium - rather than injured retinal vasculature - would allow the fluorescein to penetrate into the vitreous [8,25]. Evidence that it is the unbound fluorescein that is responsible for the leakage into the vitreous comes from our experiment with the insulin-treated diabetic rats. Although we measured identical total (free plus bound) fluorescein concentrations in control and insulin-treated diabetic rats, the latter showed higher free plasma fluorescein and higher vitreous fluorescein levels.

Our findings should also be of relevance to clinical work. In patients, we believe that vitreous fluorophotometric data can only be interpreted if both fluorescein pharmacokinetics and protein binding are considered, since both influence the vitreous fluorescein accumulation and both may be altered by disease and drug treatment. Many of the published studies lack these important data and are therefore inconclusive.

In summary, vitreous fluorescein concentration can be measured reliably in pigmented rats by vitreous fluorophotometry. Accumulation of fluorescein in the vitreous depends on plasma fluorescein levels. Diabetic rats exhibit higher vitreous to plasma fluorescein ratios, accelerated plasma fluorescein elimination and decreased protein binding than age-matched controls. Insulin treatment leads to a normalization of the plasma fluorescein elimination and of the changed vitreous to plasma fluorescein ratios in diabetic rats.

Acknowledgments. We wish to thank Dr. E. Lorch for discussion and advice in the preparation of this manuscript, L. Burcklen and M. Kerker for expert technical assistance and M. Rimelin for typing the manuscript.

\section{References}

1. Cunha-Vaz J, Abren JF, Campos AJ, Figo GM (1975) Early breakdown of the blood-retinal barrier in diabetes. Brit $\mathbf{J}$ Ophthalmol 59: $649-656$

2. Waltman SR, Krupin T, Kilo C, Becker B (1979) Vitreous fluorophotometry in adult-onset diabetes mellitus. Am J Ophthalmol 88: 342-345

3. Krupin T, Waltman SR, Oestrich C, Santiago J, Ratzan S, Kilo C, Becker B (1978) Vitreous fluorophotometry in juvenile-onset diabetes mellitus. Arch Ophthalmol 96: 812-814

4. White NH, Waltman SR, Krupin T, Santiago JU (1982) Reversal of abnormalities in ocular fluorophotometry in insulin-dependent diabetes after five to nine months of improved metabolic control. Diabetes 21: 80-85

5. Prager TC, Chu HH, Garcia CA, Anderson RE, Field JB, Orzeck
EA, Comstock JP (1983) The use of vitreous fluorophotometry to distinguish between diabetics with and without observable retinopathy: effect of vitreous abnormalities on the measurement. Invest Ophthalmol Vis Sci 24: 57-65

6. Kjaergaard JJ, Ohrt V (1983) Ocular fluorophotometry in insulintreated diabetic patients with and without retinopathy. Int $\mathbf{J}$ Microcirc Clin Exp 2: 207-213

7. Waltman SR, Krupin T, Hanish S, Oestrich C, Becker B (1978) Alteration of the blood retinal barrier in experimental diabetes mellitus. Arch Ophthalmol 96: 878-879

8. Tso MO, Cunha-Vaz JG, Shih CY, Jones CW (1980) Clinicopathologic study of blood-retinal barrier in experimental diabetes mellitus. Arch Ophthalmol 98: 2032-2040

9. Kernell A, Arnquist H (1983) Effect of insulin treatment on the blood retinal barrier in rats with streptozotocin induced diabetes. Arch Ophthalmol 101: 968-970

10. Krupin T, Waltman SR, Sharp DW, Oestrich C, Feldman SD, Becker B, Ballinger WF, Lacy PE (1979) Ocular fluorophotometry in streptozotocin diabetes mellitus in the rat: Effect of pancreatic islet isografts. Invest Ophthalmol Vis Sci 18: 1185-1190

11. Klein R, Wallow IH, Ernest JT (1980) Fluorophotometry. III. Streptozotocin-treated rats and rats with pancreatectomy. Arch Ophthalmol 98: 2235-2237

12. Smith SS, Frank S, Ashburn JR, Pilkerton AR, Recant L (1982) Vitreous fluorophotometry in three models of experimental diabetes mellitus. Retina 2: 121-125

13. Klein R, Emest JT, Engerman RL (1980) Fluorophotometry: I. Technique. Arch Ophthalmol 98: 2231-2232

14. Prager TC, Wilson DJ, Avery GD, Merit JH, Garcia CA, Hoper G, Andeson RE (1981) Vitreous fluorophotometry: identification of sources of variability. Invest Ophthalmol Vis Sci 21: 854-864

15. Kjaergaard JJ, Dideriksen K, Mourits-Andersen T (1983) Some aspects of the pharmacokinetics of fluorescein in normal and diabetic subjects. Int J Microcirc Clin Exp 2: 191-197

16. Kjaergaard JJ (1983) Ocular fluorophotometry in normal subjects. Int J Microcirc Clin Exp 2: 199-205

17. Lorch $\mathrm{E}$ (1969) Extraction of free fatty acids from plasma or serum in a continuous flow system. Anal Biochem 28: 307-312

18. Jensen PK, Sandahl Christiansen J, Steven K, Parving HH (1981) Renal function in streptozotocin diabetic rats. Diabetologia 21: 409-414

19. Jusko WJ, Gretch M (1976) Plasma and tissue protein binding of drugs in pharmacokinetics. Drug Metab Rev 5:43-140

20. Webb JM, Fonda M, Broner EA (1962) Metabolism and excretion patterns of fluorescein and some halogenated fluorescein dyes in rats. J Pharmacol Exp Ther 137: 141-147

21. Araie M, Sawa M, Nagataki S, Mishima S (1980) Aqueous humor dynamics in man as studied by oral fluorescein. Jap J Ophthalmol 24: $346-362$

22. Rockey JH, Weihe L (1982) Binding of fluorescein and carboxyfluorescein by normal and glycosylated human serum proteins. Ophthalmic Res 14:416-427

23. Chahal PS, Neal MJ, Kohner EM (1985) Metabolism of fluorescein after intravenous administration. Invest Ophthalmol Vis Sci 26: 764-768

24. Maepea O, Karlsson C, Alm A (1984) Blood-ocular and bloodbrain barrier function in streptozotocin-induced diabetes in rats. Arch Ophthalmol 102: 1366-1369

25. Kirber WM, Nichols CU, Grimes PA, Winegrad AI, Laties AM (1980) A permeability defect of the retinal pigment epithelium. Occurrence in early streptozotocin diabetes. Arch Ophthalmol 98: $725-728$

Received: 7 June 1985

and in revised form: 20 December 1985

Dr. F. Kaufmann

Department of Pharmaceutical Research

F. Hoffmann-La Roche \& Co.

Grenzacherstraße 124

CH-4002 Basel

Switzerland 